\title{
Periodontal Procedures adjunct to Orthodontic Treatment
}

\author{
Dr Anisha Janu,' Dr Luv Agarwal,2 Dr Kamlesh Singh,³ Dr Anil Singh4 \\ 1.2PG Resident, 3Professor, Dept of Orthodontics, 4Professor, Dept of Oral Pathology \\ Saraswati Dental College, Lucknow, India
}

Correspondence: Dr Anisha Janu; Email: anishajanu75@gmail.com

\section{ABSTRACT}

Orthodontists usually face problems with patients suffering from periodontal disease. The need for instituting periodontal treatment is of greater significance in such patients as chronic destructive periodontal diseases cause significant loss of supporting structures of the periodontium. A multidisciplinary approach should involve both orthodontist and periodontist to treat such patients and treatment progress should be evaluated periodically to implement a comprehensive treatment plan. The aim of this article is to highlight the contributing factors and procedures adjunctive to orthodontic treatment.

Key words: orthodontic therapy, ortho-perio interrelation, periodontal disease

\section{INTRODUCTION}

The objective of orthodontic therapy is to form a good occlusion relationship, improving the health of the periodontium, and enhance dental and facial esthetics. Periodontal health is an important factor in successful orthodontic tooth movement; this combined with light, consistent and controlled orthodontic force result in the regeneration of bone and allow the teeth to relocate through the alveolar bone. Appropriate forces are maintained to avoid necrosis which leads to undermining resorption. Therefore, it is mandatory to have good periodontal health not only before orthodontic treatment but also during and after orthodontic treatment.'

Many adults seek orthodontic treatment to correct malocclusion; but a significant percentage of adults also consider orthodontic treatment to prevent occurrence and progression of periodontal disease and they show better compliance which compensate for the slower tissue response. In addition, there is an increased chance of hyalinization in adults as compared to adolescents. ${ }^{2,3}$ All these factors make adult orthodontic treatment more challenging which necessitates for improvised procedures to create a functional dentition in a healthy periodontal environment.

Periodontal procedures in orthodontic patients can be broadly classified as:
1. Periodontal procedures prior to orthodontic treatment

2. Periodontal procedures during orthodontic treatment,

3. Periodontal procedures after orthodontic treatment

\section{Pre-orthodontic periodontal therapy}

It is an initial phase of periodontal therapy where periodontal infection is controlled by oral hygiene instruction, professional plaque control and root planing. Initial periodontal debridement is done by nonsurgical, subgingival root instrumentation to minimize the inflammation and to repair the tissue which is aimed for gingival health improvement. This stage of periodontal treatment is usually of about 3 month duration.

\section{Pre-orthodontic osseous surgery}

Pre-orthodontic osseous surgery depends on the type of defect e.g. osseous crater, hemiseptal defect, three-wall defect, or furcation lesion. ${ }^{4}$

Osseous craters: It is an interproximal, two-wall defect composed of the facial and lingual cortical plates that does not improve with orthodontic treatment. Generally, resective osseous surgery is required which involves reshaping of the defect and reducing the pocket depth that enhances the ability to maintain these areas during orthodontic treatment. ${ }^{5,6}$ 
Table 1: Grafts and bone substitutes

\begin{tabular}{|c|c|c|c|}
\hline \multicolumn{2}{|c|}{ Materials of bone origin } & \multicolumn{2}{|c|}{ Non-bone material } \\
\hline Vital bone grafts & Non-vital bone grafts & Organic & Inorganic \\
\hline Autografts & Allografts & - Dentine & - Calcium sulphate \\
\hline - Bone coagulum & -Lyophilized bone & - Cementum & - Bioceramics \\
\hline $\begin{array}{l}\text { - Bone from post-exodontic } \\
\text { alveoli, tubera and } \\
\text { edentulous areas }\end{array}$ & \multirow[t]{2}{*}{$\begin{array}{l}\text {-Demineralised Iyophilized } \\
\text { bone }\end{array}$} & \multirow[t]{2}{*}{ - Coral } & - Bioactive crystals \\
\hline $\begin{array}{l}\text { edentulous areas } \\
\text { - lliac crest }\end{array}$ & & & $\begin{array}{l}\text { - Polymethyl and } \\
\text { hydroxyethyl methacrylate } \\
\text { polymers }\end{array}$ \\
\hline Allografts & Xenografts & & \\
\hline - Freeze-dry bone & - Anorganic bovine bone & & \\
\hline
\end{tabular}

Three-wall intra-bony defects: The bony support of the periodontium is lost; which requires bone grafts along with resorbable or non-resorbable membranes in filling of the three-wall defects. ${ }^{7}$ Orthodontic treatment may be initiated if the result of periodontal therapy is stable. Numerous options for bone grafts are available as given in Table 1.8

Furcation defects: Furcation involvement is a condition in which bifurcation and trifurcations of multi-rooted teeth are invaded by periodontal disease process. A Nabers probe is used to diagnose tooth furcation involvement (Figure 1). The classification of furcation defects was proposed by Glickman in 1953 (Table 2). 9 Furcation defects can worsen during orthodontic therapy, hence orthodontists should take care while treating the case and rule out any furcation involvement. ${ }^{10,11}$

\section{Pre-orthodontic gingival surgery}

Gingival recession and root coverage: Alveolar bone dehiscence is a localized defect of the cortical bone which covers the teeth. When the denuded areas extend through the marginal bone, the defect is called as 'dehiscence'.12 It is a predisposing factor for the development of gingival recession. If the patient shows a minimal zone of attached gingiva or thin tissue, a free gingival graft is used. It controls the inflammation and should be done before the initiation of orthodontic tooth movement. ${ }^{12,13}$

Crown lengthening: In some orthodontic cases, where clinical crown height is short; the crown lengthening should be done using 'gingivectomy' prior to orthodontic bonding procedures. In case of patients with shorter clinical crowns in the mandibular arch, apically repositioned flap in combination with gingivectomy can be done for crown lengthening. Apically displaced flap along with gingivectomy increases the width of the attached gingiva providing better results for crown lengthening in case of mandibular teeth. ${ }^{14,15,16}$

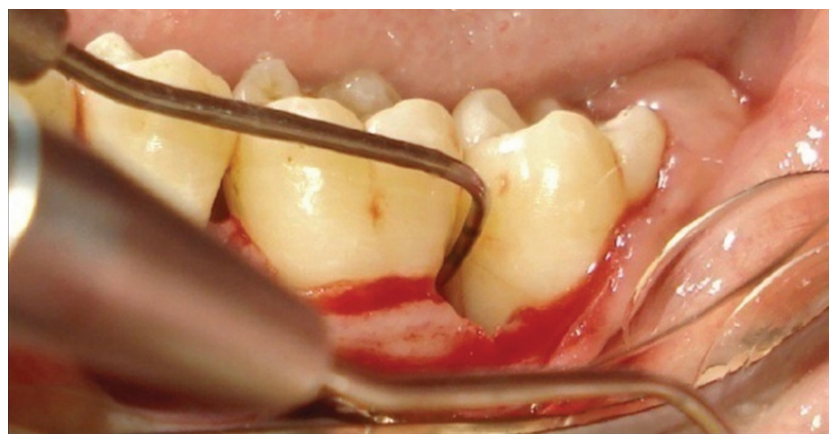

Figure 1: Grade II distal furcation

Table 2: Classification of furcation defects and their management

\begin{tabular}{|c|l|l|l|}
\hline Furcation Defect & \multicolumn{1}{|c|}{ Clinical Presentation } & Radiographic Presentation & \multicolumn{1}{c|}{ Treatment } \\
\hline Grade I & $\begin{array}{l}\text { Incipient or early lesion, slight bone } \\
\text { loss in furcation area. }\end{array}$ & No radiographic Finding & $\begin{array}{l}\text { Scaling and curettage, gingivectomy, } \\
\text { bone reshaping, odontoplasty }\end{array}$ \\
\hline Grade II & $\begin{array}{l}\text { Cul-de-sac lesion, bone destruction, } \\
\text { probe penetrates into furcation area. }\end{array}$ & $\begin{array}{l}\text { May or may not show } \\
\text { changes }\end{array}$ & Bone grafts and GTR, Gingivectomy \\
\hline Grade III & $\begin{array}{l}\text { Interradicular bone lost completely, } \\
\text { defect covered by gums, not visible } \\
\text { clinically. }\end{array}$ & $\begin{array}{l}\text { Radiolucent area seen } \\
\text { between the roots }\end{array}$ & $\begin{array}{l}\text { Gingivectomy, apical reposition } \\
\text { flap, root resection, hemisection, } \\
\text { bicuspidization }\end{array}$ \\
\hline Grade IV & $\begin{array}{l}\text { Interradicular bone is completely } \\
\text { destroyed, gums are receded \& tooth } \\
\text { furcation is completely visible. }\end{array}$ & Visible Radiographically & $\begin{array}{l}\text { Root resection, hemisection, } \\
\text { extraction }\end{array}$ \\
\hline
\end{tabular}




\section{Periodontal procedures during/after orthodontic therapy:}

Periodontal maintenance therapy: During orthodontic therapy, the patients should take care of oral hygiene and follow instructions on brushing and inter-dental aids strictly e.g. use of orthodontic brush, dental floss etc. The orthodontist should check plaque removal effectiveness and emphasize its importance in between the visits. Periodic periodontal evaluation and check-up should be carried out by the periodontist. After orthodontic therapy, patients must be motivated to maintain good oral hygiene and should maintain regular follow-up.

Fiberotomy: Circumferential supracrestal fiberotomy (CSF) is used to correct the relapse of severely rotated teeth that occurs due to rebound of elastic fibres in the supracrestal tissues. This technique consists of the insertion of a surgical blade into the gingival sulcus and sectioning the epithelial attachment surrounding the involved teeth. The transseptal fibers are transected interdentally by blade. No surgical dressings are needed and clinical healing usually completes by 7-10 days. ${ }^{17}$

Frenotomy / Frenectomy: Abnormal frenum attachment results when a $v$-shaped bony cleft is formed between the two central incisors and a thick frenum resists orthodontic forces and is responsible for the relapse of space closure (Figure 2). The mandibular frenum is associated with a decreased vestibular depth and an inadequate width of the attached gingiva. ${ }^{18}$ The area is anaesthetized with local infiltration using $2 \%$ lignocaine with 1:80000 adrenaline. The frenum is engaged with a haemostat and inserted into the depth of the vestibule and incisions are placed on the upper surface of the haemostat. The triangular resected portion of the frenum is removed with the haemostat. The edges of the diamond shaped wound are sutured with 4-0 black silk with interrupted sutures. The area is covered with periodontal pack. The pack and the sutures are removed one week post-operatively. ${ }^{19}$ Frenectomy is more commonly performed procedure; however the undesirable loss of interdental papilla is a common complication encountered with this procedure. Hence, the frenotomy despite being a superficial procedure, is esthetically preferable..$^{20}$

Gingivectomy/Gingivoplasty: Gingivoplasty is defined as surgical recontouring of the gingiva in order to achieve a physiologic contour. It is used to treat gingival enlargements in orthodontic patients. In this procedure, the reshaping of attached gingiva is done to provide more esthetic and functional contours. It involves a pocket marker or a periodontal probe which is used to outline the base of the pocket with small bleeding points; these bleeding points form a dotted line that outlines the incision. The incision begins just apical to the bleeding points and the blade is held in such a manner that the incision is close to the bone for complete removal of pocket. The blade passes through the tissue to the tooth fully; Orban interproximal knife is used to free the interproximal tissue. The tissue is removed by using a hoe or heavy scalers once it is free. ${ }^{21}$

Corticotomy-assisted Orthodontic Treatment (CAOT): It is defined as a surgical procedure where only the outer cortical bone is cut and the medullary bone is not changed. ${ }^{22,23}$ Full thickness buccal and lingual flaps are raised and vertical osseous grooves are placed which extends from below the interproximal margin to beyond the tooth apices and then horizontal grooves are connected with the vertical cuts (Figure 3). ${ }^{24}$ The procedure is very effective in Class I malocclusion with crowding, Class II malocclusions which requires expansion or extractions, and mild Class III malocclusions.

Wilckodontics: Wilckodontics is a new sub-branch which provides an increased alveolar bone volume after orthodontic treatment. This is also called the Periodontallyaccelerated osteogenic orthodontic procedure that combines alveolar bone corticotomy, bone grafting and orthodontic forces application. It is based on regional acceleratory phenomenon (RAP). It is a bone healing pattern leading to increased width of alveolar bone, short treatment time, increased post-treatment stability, and decreased apical root resorption. ${ }^{25}$ PAOO technique creates rapid orthodontic tooth movement and reduces side effects like inadequate basal bone, root resorption, tooth devitalisation, periodontal infection and relapse. The teeth can be moved two to three times faster. In certain cases the activated bone and exposed root surfaces are covered with the bone grafting material (a combination of demineralised freeze dried bone allograft, DFDBA and xenograft extender) (Figure 4)..$^{26,27}$

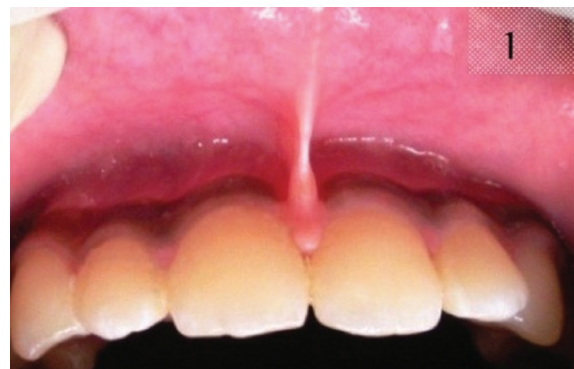

Figure 2: Papillary type of frenal attachment

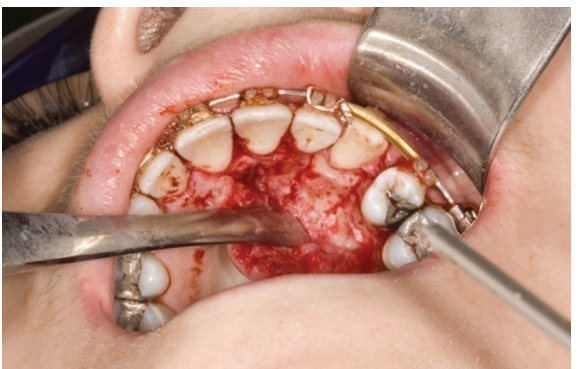

Figure 3: Corticotomy

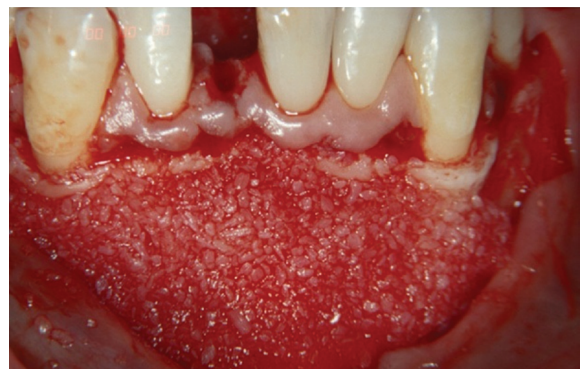

Figure 4: Particulate bone graft layered over decorticated alveolar bone 


\section{Periodontal maintenance therapy after orthodontic therapy}

After completion of orthodontic treatment, it should be made mandatory that the patient should follow periodontal maintenance for at least 6 months. After orthodontic appliance debonding/ debanding; periodontal service shall be required to eliminate periodontal pockets, assist in adequate bone remodelling and narrowing of periodontal space. A radiographic reevaluation should be carried out by the periodontist to evaluate further periodontal needs.

\section{DISCUSSION}

The orthodontic intervention can only be initiated when the periodontal inflammatory process is controlled and stable periodontal condition is achieved by the elimination of periodontal pockets in periodontally compromised patients. Inter-disciplinary approach augmented by patient education and good oral hygiene care transform patients with unattractive dentition, irregular teeth and inflamed periodontium into individuals with healthy attractive dentition and radiant smile. Therefore, orthodontic and periodontal considerations should be properly addressed for stable and esthetic outcome.

\section{REFERENCES}

1. Vincent G. Kokich. Esthetics: The orthodontic-periodontic-restorative connection. Seminars in Orthodontics 1996; 2(1):21-30.

2. Perrigaard J, Blixencrone-Moller T. Why do adults seek orthodontic treatment? In: Proceedings of 64th Congress of European Orthodontic Society, London: 1988 July; p. 61 A.

3. Ong MM, Wang HL. Periodontic and orthodontic treatment in adults. Am J Orthod Dentofacial Orthop 2002; 122:420-8.

4. Bhaskar N, Garg A, Gupta V. Periodontics as an adjunct to clinical orthodontics. Ind J Multidiscip Dent 2013; 3:756-61.

5. Ochsenbein C, Ross SA. Re-evaluation of osseous surgery; Dent Clin North Am 1969; 13:87-102.

6. Ochsenbein C, Bohannan HM. The palatal approach to osseous surgery II. Clinical application. J Periodontal1964; 35:54.

7. Yadav SV, Narula SC, Sharma KR, Tewari S, Yadav R. Clinical evaluation of guided tissue regeneration combined with autogenous bone or autogenous bone mixed with bioactive glass in intrabony defects. J Oral Sci 2011; 53:481-83.

8. Grover V, Kapoor A, Malhotra R, Uppal RS. Evaluation of the efficacy of a bioactive synthetic graft material in the treatment of intrabony periodontal defects. J Indian Soc Periodontol 2013; 17:491-503.

9. Glickman I. Clinical Periodontology. Philadelphia. Saunders.10 th ed. 1953;Pp. 992-3.

10. Cattabriga M, Pedrazzoli V, Wilson Jr. TG. The conservative approach in the treatment of furcation lesions. Periodontol 2000; $22: 133-53$.

11. Lindhe J, Lang PL, Karring T. Clinical Periodontology and implant dentistry 2008. 5th Ed. Blackwell Publishing; Chapter 39: pp 823-47.

12. Dorfman HS. Mucogingival changes resulting from Mandibular incisor tooth movement. Am J Orthod 1978; 74:286.

13. Steiner GG, Pearson JK, Ainamo J. Changes of the marginal periodontium as a result of labial tooth movement in monkeys. J Periodontol $1981 ; 52: 314-20$.

14. Dolt AH, Robbins JW. Altered passive eruption: An etiology of short clinical crowns. Quintessence Int 1997; $28: 363-72$.

15. Robbins JW. Differential diagnosis and treatment of excess gingival display. Pract Periodont Aesthet Dent. 1999; 11 (2):265-272.

16. Morrow LA, Robbins JW, Jones WL, Wilson NHF. Clinical crown length changes from age 12-19 years: A longitudinal study. J Dent. 2000; 28:469-473

17. Edwards JG. A Long term prospective evaluation of the circumferential supracrestal fiberotomy in alleviating orthodontic relapse. Am J Orthod Dentofacial Orthop 1988; 93: 380-387.

18. Huang WJ, Creath CJ. The midline diastema: a review on its etiology and treatment. Pediatric Dentistry 1995; 17:171-9.

19. Devishree. Frenectomy: A review with the reports of surgical techniques. J Clin Diag Res. 2012; 6:8.

20. Edwards JG. The diastema, the frenum, frenotomy: A clinical study. Am J Orthod 1977; 71:489-508.

21. Carranza F, Neumann MG. Clinical Periodontology 8th Ed. Contemporary Periodontics. 2nd ed. William R Proffit; 323:593-596.

22. Hassan AH, Al-Fraidi AA, Al-Saeed SH. Corticotomy-assisted orthodontic treatment: Review. Open Dent J. $2010 ; 4: 159-164$.

23. Yaffe A, Fine N, Binderman I. Regional accelerated phenomenon in the mandible following mucoperiosteal flap surgery. J Periodontol $1994 ; 65: 79-83$

24. Patel N. Corticotomy assisted orthodontics: A review of surgical technique and literature. OA Dentistry 2014; 25:2(1):3.

25. Murphy K, Wilcko MT. Periodontal accelerated osteogenic orthodontics. A description of surgical technique. J Oral Maxillofac Surg. 2009; 67:21-60.

26. Mihran WL, Murphy NC. The Orthodontist's role in 21st century periodontic-prosthodontic therapy. Semin Orthod 2008; $14: 272-289$.

27. Palomo L, Palomo JM, Bissada NF. Salient periodontal issues for the modern biologic orthodontist. Semin Orthod 2008; 14:229-245. 